\title{
Consolidated bioprocessing of Populus using Clostridium (Ruminiclostridium) thermocellum: a case study on the impact of lignin composition and structure
}

\author{
Alexandru Dumitrache ${ }^{1,2}$, Hannah Akinosho 1,2,3,4, Miguel Rodriguez Jr. 1,2, Xianzhi Meng 2,3,5, \\ Chang Geun Yoo ${ }^{1,2,4}$, Jace Natzke ${ }^{1,2}$, Nancy L. Engle ${ }^{1,2}$, Robert W. Sykes ${ }^{6}$, Timothy J. Tschaplinski ${ }^{1,2}$, \\ Wellington Muchero ${ }^{1,2}$, Arthur J. Ragauskas ${ }^{1,2,4,7}$, Brian H. Davison ${ }^{1,2}$ and Steven D. Brown 1,2*
}

\begin{abstract}
Background: Higher ratios of syringyl-to-guaiacyl (S/G) lignin components of Populus were shown to improve sugar release by enzymatic hydrolysis using commercial blends. Cellulolytic microbes are often robust biomass hydrolyzers and may offer cost advantages; however, it is unknown whether their activity can also be significantly influenced by the ratio of different monolignol types in Populus biomass. Hydrolysis and fermentation of autoclaved, but otherwise not pretreated Populus trichocarpa by Clostridium thermocellum ATCC 27405 was compared using feedstocks that had similar carbohydrate and total lignin contents but differed in S/G ratios.
\end{abstract}

Results: Populus with an S/G ratio of 2.1 was converted more rapidly and to a greater extent compared to similar biomass that had a ratio of 1.2. For either microbes or commercial enzymes, an approximate $50 \%$ relative difference in total solids solubilization was measured for both biomasses, which suggests that the differences and limitations in the microbial breakdown of lignocellulose may be largely from the enzymatic hydrolytic process. Surprisingly, the reduction in glucan content per gram solid in the residual microbially processed biomass was similar (17-18\%) irrespective of $\mathrm{S} / \mathrm{G}$ ratio, pointing to a similar mechanism of solubilization that proceeded at different rates. Fermentation metabolome testing did not reveal the release of known biomass-derived alcohol and aldehyde inhibitors that could explain observed differences in microbial hydrolytic activity. Biomass-derived $p$-hydroxybenzoic acid was up to ninefold higher in low S/G ratio biomass fermentations, but was not found to be inhibitory in subsequent test fermentations. Cellulose crystallinity and degree of polymerization did not vary between Populus lines and had minor changes after fermentation. However, lignin molecular weights and cellulose accessibility determined by Simons'staining were positively correlated to the $S / G$ content.

Conclusions: Higher S/G ratios in Populus biomass lead to longer and more linear lignin chains and greater access to surface cellulosic content by microbe-bound enzymatic complexes. Substrate access limitation is suggested as a primary bottleneck in solubilization of minimally processed Populus, which has important implications for microbial deconstruction of lignocellulose biomass. Our findings will allow others to examine different Populus lines and to test if similar observations are possible for other plant species.

Keywords: Lignin, Syringyl, Guaiacyl, S/G ratio, Consolidated bioprocessing, Populus, Clostridium thermocellum, Molecular weight

\footnotetext{
*Correspondence: brownsd@ornl.gov

1 Biosciences Division, Oak Ridge National Laboratory, Oak Ridge, TN

37831, USA

Full list of author information is available at the end of the article
} 


\section{Background}

Recent advancements in lignocellulosic biofuel strategies have shown increased adoption and improved conversion of dedicated bioenergy feedstocks. For example, consolidated bioprocessing (CBP) growth on very high loads of minimally processed switchgrass has been described for Caldicellulosiruptor bescii [1]. Yeast-based simultaneous saccharification and fermentation (SSF) and consolidated bioprocessing with Clostridium thermocellum have shown improved bioconversion performance for switchgrass with reduced lignin content [2]. Bioconversion performances for Sacharomyces cerevisiae SSF and several CBP approaches have been assessed for switchgrass (Panicum virgatum) under different conditions [3]. C. thermocellum has one of the highest rates for cellulose utilization [4]. Metabolic engineering has generated strains that produce $70 \%$ of theoretical ethanol yield on Avicel and ethanol titers up to $73.4 \mathrm{mM}$, although further engineering is required [5].

Populus is a fast-growing woody bioenergy feedstock investigated for utilization in large scale bioconversion to alcohols $[6,7]$. Its inherent recalcitrance to enzymatic and microbial deconstruction is one of the largest impediments to large scale, economically feasible biofuel production. Understanding Populus properties responsible for its resistance to degradation will aid in the generation of low recalcitrance plants. Lignin is an important component of lignocellulosic biomass, which is thought to act as a physical barrier toward the accessible surface of carbohydrates and adsorb and inactivate cellulases to restrict enzymatic hydrolysis [8]. Lignin is a branched heterogeneous polymer that makes up 16-28\% of the content of undomesticated natural variants of Populus trichocarpa [9]. When incorporated into lignin, the primary monolignols (Fig. 1) form three units: $p$-hydroxyphenylpropane $(\mathrm{H})$, syringyl $(\mathrm{S})$, and guaiacyl $(\mathrm{G}) . \mathrm{S}$ and $G$ are the predominant units in the hardwood lignin backbone and vary in an S/G ratio between 1.0 and 3.0 [9]. Lignin is most commonly linked through a labile arylglycerol- $\beta$-aryl ether $(\beta-O-4)$ bond [10].

Compositionally, these lignin units differ by the absence of the methoxy group in position five on the benzene ring of the $\mathrm{G}$ unit, which results in the potential creation of two additional highly resistant bonds [11], the 5-5 and the $\beta-5$ linkages (Fig. 1). This fundamental difference has been theorized to prompt differences in biomass<smiles>[R]CCc1cc(C)c(O)c(-c2cc(CC[R])cc(OC)c2O)c1</smiles> 
degradability when the $\mathrm{S}$ and $\mathrm{G}$ lignin content varies: G-rich lignin could promote thinner cell walls that are easier to degrade [12], or it may lead to denser polymer crosslinking with increased resistance to degradation [13]; S-rich lignin may form predominantly linear shorter chains with thermoplastic properties more favorable to degradation, particularly by hydrothermal pretreatments [9].

Despite the emerging hypotheses, current literature does not hold a unified mechanistic understanding on the role of lignin in the biological breakdown of lignocellulosic biomass. Still, there is general agreement that lignification significantly inhibits deconstruction, in particular, a strong negative correlation is seen between total lignin content and sugar release by free-enzyme hydrolysis $[14,15]$. However, literature data do not show a generalized association between lignin composition and cellulose degradability in lignocellulose. Several reports found no discernable correlation between lignin S/G content and saccharification levels in alfalfa transgenics [15], synthetic cell wall complexes [16], and untreated Arabidopsis thaliana mutants [17]. A high S/G ratio was found to adversely affect xylose release by acid hydrolysis in Populus [13], the enzymatic solubilization of maize [18], and transgenic Populus degradation by wood-decay fungi [19]. At the same time, high $\mathrm{S} / \mathrm{G}$ was found to improve the saccharification of pretreated A. thaliana mutants [17], the efficiency of Kraft pulping [20], and enzymatic sugar release in undomesticated Populus [9]. A challenge in comparing these published results is that many other properties beyond $\mathrm{S} / \mathrm{G}$ ratio may also vary in these studies. These examples demonstrate that lignin S and G variations can be neutral or relevant depending on plant species, transgenic modifications, biomass pretreatments, and the choice of degradation agent or method.

For undomesticated natural variants of Populus trichocarpa, the biomass tested in the current study, Studer and collaborators [9] found an S/G ratio above 2.0 to generally improve enzymatic hydrolysis, while the worst nine out of 47 performers had either very low S/G ratios (below 1.2) or very high total lignin content (above $27.8 \%$ ). Cellulose properties, such as the degree of polymerization [21] and crystallinity [22], have also been of interest for characterization of lignocellulose recalcitrance and were investigated in this study in relation to lignin.

In this study, for the first time, we address whether lignin S/G variations have an impact on the consolidated bioprocessing of Populus biomass by a model cellulolytic organism, Clostridium thermocellum ATCC 27405. We evaluate the bioconversion performance of Populus individuals with similar average total lignin values and high or low $\mathrm{S} / \mathrm{G}$ compositions to determine whether microbes have differential access to sugars, whether potential inhibitor release was linked to lignin composition, and whether the abundance of S and G-units was responsible for changes in biomass structural properties before and after fermentation (i.e., lignin and cellulose molecular weights, cellulose crystallinity, and degree of polymerization).

\section{Results}

\section{Initial microbial bioconversion screening of Populus} natural variants

Populus natural variants were screened and selected on the basis of average and similar total lignin $(\sim 24 \%)$ content. A subsection was assayed for primary carbohydrate content (i.e., glucose, xylose, galactose, arabinose, and mannose) and the lignin S/G ratio. These selected Populus had very similar sugar contents (Additional file 1: Figure A.1). Three with average $S / G$ ratios $(\sim 2.1)$ and one with the lowest possible S/G ratio $(\sim 1.2)$ were chosen for bioconversion performance assessment. Microbial CBP screening of these Populus individuals revealed a very similar performance in samples with equal S/G ratios, and a significantly lower conversion of the Populus with very low S/G content (Fig. 2). The results are consistent with reported solubilization of undomesticated Populus with commercial enzyme mixtures [9].

To investigate what was responsible for the large discrepancy in the degradability of Populus with seemingly comparable sugar and total lignin content, but with a two-fold change in S/G content, two individuals were selected for further comparative analyses and will be referred to as the "low S/G" (natural variant BESC102) and the "high $S / G$ " (natural variant HARA-26-2) phenotypes.

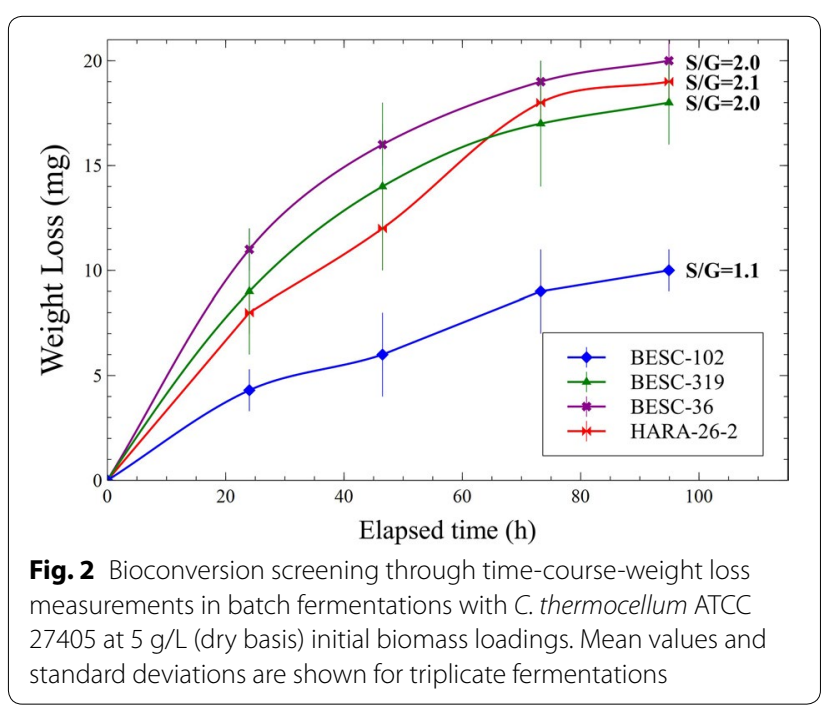


Consolidated bioprocessing (CBP): microbial hydrolysis and fermentation of low and high S/G Populus phenotypes Microbial hydrolysis and fermentation of $20 \mathrm{~g} / \mathrm{L}$ biomass samples (approximately 8-8.8 g/L glucan) in $\mathrm{pH}$-controlled bioreactors showed total solid solubilization of $12 \%$ in low S/G and $20 \%$ in high S/G Populus (i.e., a $50 \%$ relative difference-calculated as absolute difference normalized to average solubilization for both lines). Ethanol yield (mg/g glucan) was 2.9-fold higher for the high S/G Populus, although fermentations of low S/G samples had their metabolic output shifted more toward acetate production-reported here as normalized to total biomass (Fig. 3). Subtracting the end-point biomass-derived acetate of control (uninoculated) samples from the total acetate in fermentation samples, the rough acetate to ethanol ratio was calculated to be 2.9:1 and 5.4:1 for the high S/G and the low S/G biomass conversions, respectively. Xylose release was proportional to total solid solubilization in both cases (data not shown). Control fermentations with $10 \mathrm{~g} / \mathrm{L}$ glucan (Avicel) showed near-complete solubilization in less than $24 \mathrm{~h}$ (Additional file 1: Figure A.2). Compositional analysis of primary sugars in the two Populus phenotypes, before and after microbial bioconversion revealed an equal $15 \%$ reduction (g/g solid, dry basis) in the measured total carbohydrates. Glucose recorded the largest reductions in absolute values; however, with very similar relative changes (per gram solid), at 17 and $18 \%$ lower post-fermentation glucan content in the low S/G and the high S/G phenotypes, respectively (Fig. 4).

\section{Separate hydrolysis and fermentation (SHF): free-enzyme hydrolysis and yeast fermentation of low and high S/G Populus phenotypes}

To test whether the large differences observed under CBP conversion were largely at the hydrolysis level, the two Populus phenotypes were also processed with a mixture of commercial cellulases, hemicellulases, and a $\beta$-glucosidase at $50{ }^{\circ} \mathrm{C}$. A $52 \%$ relative difference in glucose release was measured in favor of the high S/G phenotype. Xylose release measured a similar $60 \%$ relative difference (data not shown), and the subsequent yeast fermentation of solubilized sugars had similar conversion efficiency to ethanol (i.e., ethanol yield/glucose release, under $5 \%$ relative difference) (Fig. 5), indicating no biomass-derived adverse effect on the yeast metabolism.

\section{GC-MS metabolome analysis of CBP bioconversions for identification of potential inhibitor release}

In order to test whether biomass-derived inhibitors were contributors to differences in biomass solubilization during microbial hydrolysis, extracellular bioreactor metabolome samples were analyzed at time zero, 71 , and $140 \mathrm{~h}$. Unsurprisingly, guaiacyl lignans were released in higher proportion from the low S/G Populus, while syringyl
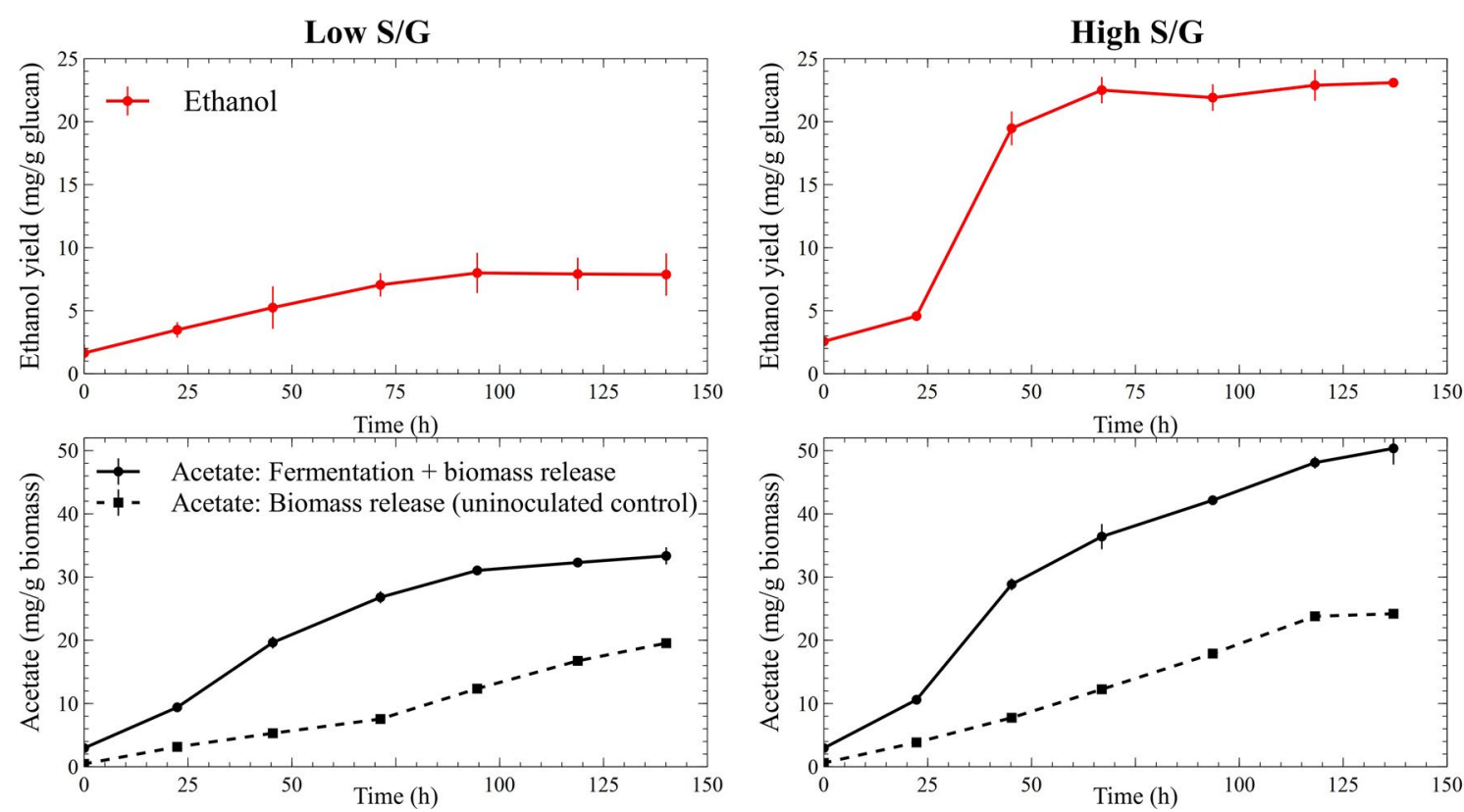

Fig. 3 A 2.9-fold ethanol yield increase in the consolidated bioprocessing of high S/G Populus biomass over the low S/G variant (top); biomassderived acetate (below, dotted line) measured in un-inoculated bioreactor controls and total acetate measured in CBP bioreactors (below, solid line)_fermentative acetate is approximately the difference between these two series. Mean values and standard deviations are shown for triplicate fermentations 

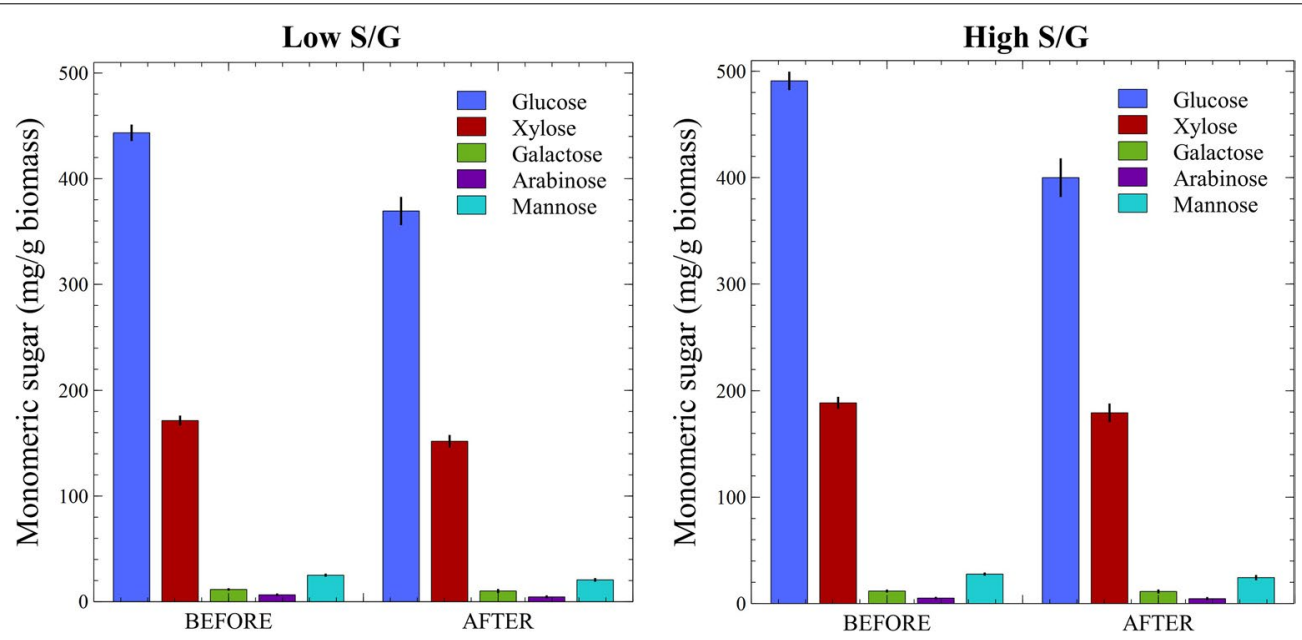

Fig. 4 Sugar content per gram solid in low S/G (left) and high S/G (right) Populus before and after consolidated bioprocessing. Mean values and standard deviations are shown for solids of triplicate fermentations

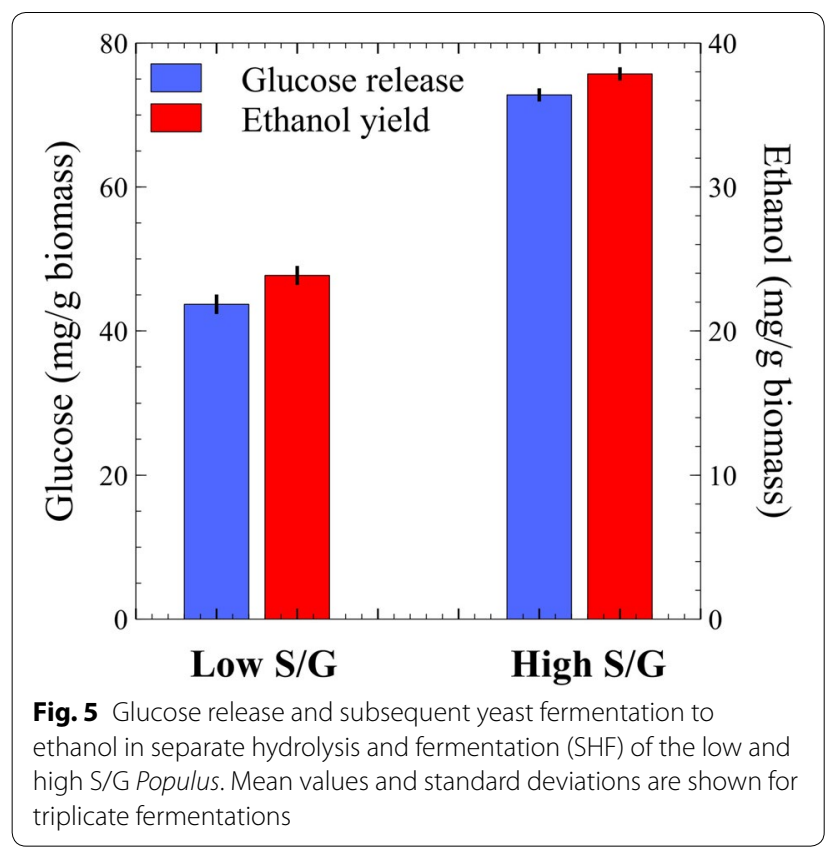

lignans were released in higher proportion from the high S/G biomass (Table 1). However, the very low detected concentrations were below what was considered inhibitory. The most common biomass-derived inhibitors (e.g., lignin precursors, HMF, furfural) were also not detected in the fermentation medium of either feedstock.

Among the identified metabolites, $p$-hydroxybenzoic acid was released in higher concentrations (up to $6.8 \mu \mathrm{g} /$ $\mathrm{mL}$ ) and also showed the most pronounced fold-differences between the two Populus phenotypes. In order to test the potential inhibitory effect of $p$-hydroxybenzoic acid, it was added to fermentations of the high S/G Populus at two concentrations and was found to have no measurable impact on fermentation performance (Fig. 6).

\section{Biomass characterization: cellulose degree of polymerization, crystallinity, and lignin molecular weight}

Cellulose was isolated from the low and high S/G biomasses, before and after CBP fermentation. The numberaverage and the weight-average degree of polymerization $\left(D_{n}\right.$ and $D P_{w}$, respectively) for cellulose were calculated from molecular weight determinations obtained by gel permeation chromatography (GPC) (Fig. 7). The high ratio S/G Populus had marginally longer cellulose chains (i.e., $\mathrm{DP}_{\mathrm{n}}$ ); however, the difference became statistically not significant after bioconversion $(p=0.41)$. The degree of polymerization increased in both feedstocks following microbial hydrolysis by roughly 19-24 units. Polydispersity measurements provide indications of the broadness of molecular weight distributions for polymers. Polydispersity $\left(\mathrm{DP}_{\mathrm{w}} / \mathrm{DP}_{\mathrm{n}}\right)$ calculations indicated that the low $\mathrm{S} / \mathrm{G}$ Populus had a wider distribution of cellulose molecular weights (19.1 for low S/G and 16.6 for high S/G Populus), which did not change to a great extent after fermentation. Cellulose crystallinity was assessed using ATR-FTIR (attenuated total reflectance-Fourier transform infrared) to determine its relationship to $S / G$ ratio. Peaks at 1430 and $898 \mathrm{~cm}^{-1}$ in the FTIR spectrum are sensitive to changes in crystalline and amorphous cellulose content $[23,24]$ and thus, the ratio of these peaks provides for comparisons of cellulose crystallinities (Fig. 7). The low S/G Populus displayed an initially higher crystallinity ratio $(p=0.22)$ compared to the starting high $S / G$ 
Table 1 Time-course GC-MS metabolome analysis of CBP bioconversions; aqueous concentrations ( $\mathrm{mg} / \mathrm{L}$ ) and the fold change (low S/G to high S/G) of potential biomass-derived inhibitors

\begin{tabular}{|c|c|c|c|c|c|c|c|c|c|}
\hline \multirow[t]{2}{*}{ Metabolite } & \multicolumn{3}{|l|}{$\mathrm{Oh}$} & \multicolumn{3}{|l|}{$71 \mathrm{~h}$} & \multicolumn{3}{|l|}{$140 \mathrm{~h}$} \\
\hline & Low S/G & High S/G & Fold change & Low S/G & High S/G & Fold change & Low S/G & High S/G & Fold change \\
\hline p-Hydroxybenzoic acid & 1.28 & 0.14 & 9.33 & 4.54 & 0.56 & 8.08 & 6.82 & 1.09 & 6.26 \\
\hline 4-Hydroxyphenethyl alcohol & 0.02 & 0.01 & 1.50 & 0.26 & 0.77 & $\underline{0.34}$ & 0.46 & 1.73 & $\underline{0.27}$ \\
\hline 11.64347 & 0.38 & 0.16 & 2.37 & 4.62 & 0.97 & 4.78 & 8.23 & 1.74 & 4.72 \\
\hline 11.00218100 & 2.13 & 0.55 & 3.89 & 5.16 & 1.28 & 4.04 & 4.20 & 1.30 & 3.23 \\
\hline 10.92218100277 & 3.38 & 1.08 & 3.14 & 9.32 & 3.71 & 2.51 & 7.73 & 2.41 & 3.21 \\
\hline 14.90 Guaiacyl lignan & 1.33 & 0.36 & 3.73 & 1.15 & 0.36 & 3.19 & 0.72 & 0.28 & 2.61 \\
\hline 14.96 Guaiacyl lignan & 2.30 & 0.68 & 3.36 & 2.27 & 0.81 & 2.80 & 1.67 & 0.70 & 2.37 \\
\hline Guaiacylglycerol & 0.09 & 0.04 & 2.17 & 0.10 & 0.05 & 2.20 & 0.09 & 0.05 & 2.00 \\
\hline 15.52 Syringyl lignan & 0.09 & 0.17 & $\underline{0.55}$ & 0.12 & 0.25 & $\underline{0.49}$ & 0.13 & 0.28 & $\underline{0.46}$ \\
\hline 15.44 Syringyl lignan & 0.05 & 0.10 & $\underline{0.55}$ & 0.05 & 0.10 & $\underline{0.47}$ & 0.04 & 0.10 & $\underline{0.38}$ \\
\hline Syringylglycerol & 0.09 & 0.09 & 1.04 & 0.13 & 0.12 & 1.09 & 0.12 & 0.13 & 0.92 \\
\hline
\end{tabular}

Italicized values: higher in the Low S/G poplar bioconversion; Italicized underlined values: higher in the High S/G poplar bioconversion

Only metabolites released with greater than two-fold difference between the low and high S/G phenotypes are shown (with the exception of syringyl glycerol). Numerical labels for unidentified metabolites are denoted by retention time and key mass-to-charge $(\mathrm{m} / \mathrm{z})$ ratios

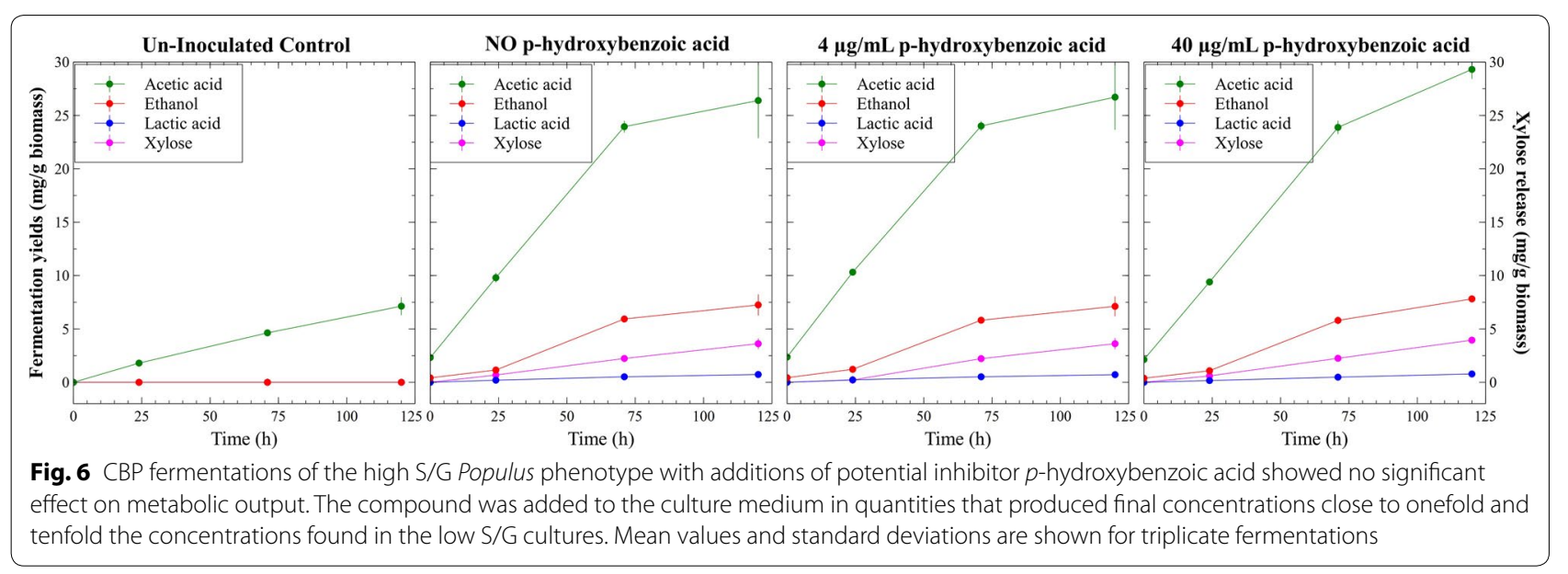

Populus, which decreased following CBP conversion $(p=0.29)$. The high $\mathrm{S} / \mathrm{G}$ biomass started with a lower initial crystallinity ratio that increased after microbial conversion $(\mathrm{p}=0.46)$. However, differences were not statistically significant at $95 \%$ confidence and the wider variations may be credited to heterogeneity in the small subsamples used in this analysis.

The crystallinity indices as determined by NMR ranged between 49.6 and $54.0 \%$, which are typical values for poplar [25]. The crystallinity indices indicate minor differences between the samples. The low S/G ratio biomass experienced a $4 \%$ decrease in crystallinity, whereas the high $\mathrm{S} / \mathrm{G}$ ratio biomass experienced a negligible change before and after CBP. The CrIs determined from NMR were in good agreement with the ATR-FTIR absorbance ratios for the samples with the exception of the unfermented high S/G poplar. Hydrogen bonding with water broadens peaks in the IR spectrum, which may account for the difference observed.

Lignin was also isolated from the two Populus phenotypes before and after CBP conversion, and its molecular weight (in $\mathrm{g} / \mathrm{mol}$ ) was determined by GPC. The results pointed to the most meaningful difference between these Populus individuals (Fig. 8), where the high S/G variant had significantly larger lignin molecular weights than the low S/G biomass $(p<0.01)$ in both the initial and the CBP-processed samples. Post-fermentation biomass had modest lignin $M_{\mathrm{w}}$ increases in both phenotypes (although with low statistical significance, $p=0.13$ and $p=0.11$ ). The polydispersity indices were not different between 

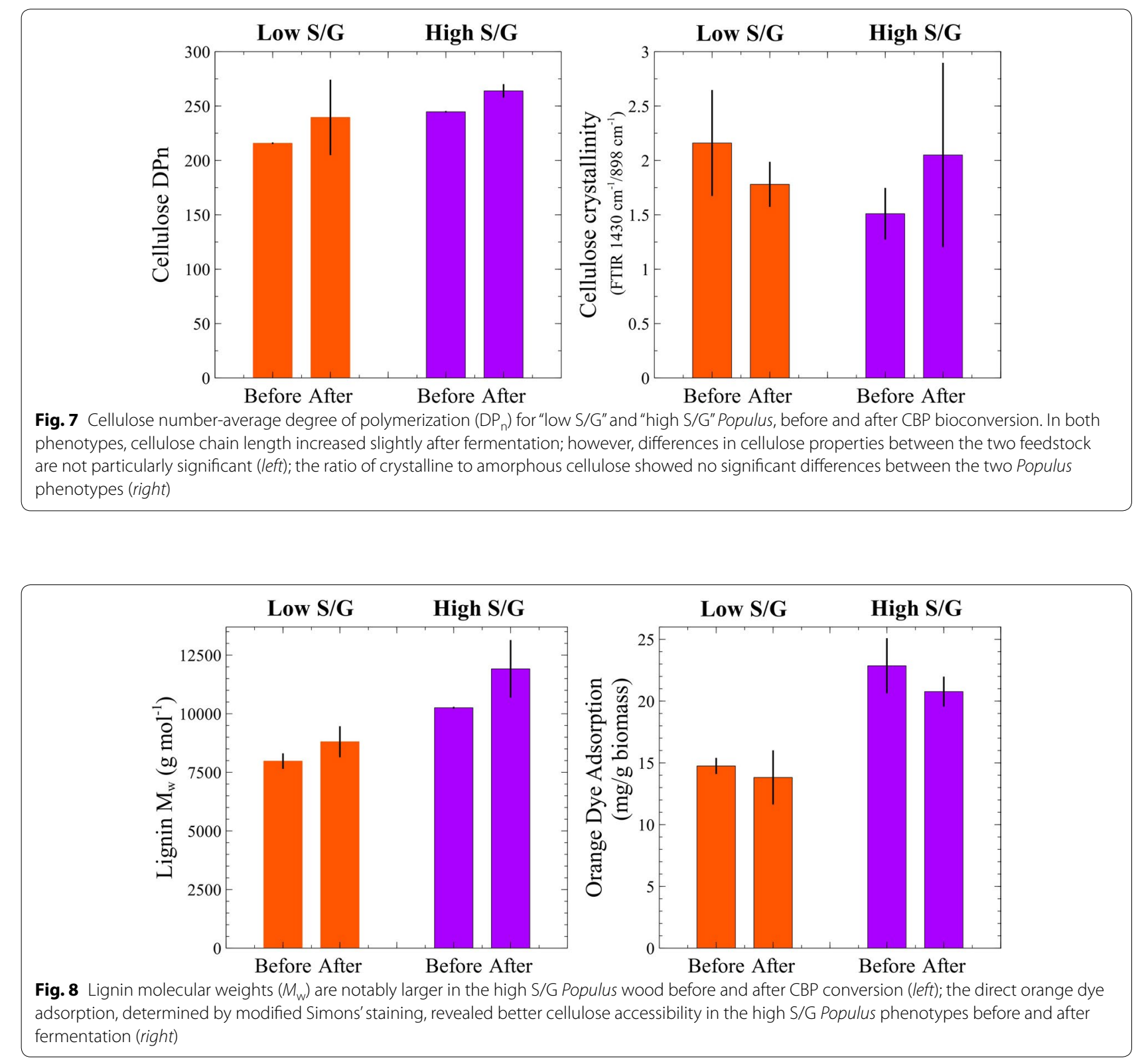

the $\mathrm{S} / \mathrm{G}$ variants (i.e., 2.2) and marginally increased to 2.4 only in the high S/G Populus after CBP conversion.

\section{Simons' staining: cellulose accessibility measurements}

Simons' staining utilizes mixtures of a small blue dye $(\sim 1 \mathrm{~nm}$ molecular diameter) and a larger orange dye ( 5$36 \mathrm{~nm})$ to characterize cellulose surface porosity [26]. In this study, we report the orange dye adsorption values (Fig. 8), because the orange dye has a higher affinity to cellulose and is thought to provide a good estimation of enzymatic accessibility to cellulose surface area due to the dye's molecular weight similarity to cellulases and its high binding affinity [27]. The high S/G Populus had better orange dye adsorption than the low S/G Populus $(p=0.04)$; and in both cases, these values decreased by small, although statistically not significant, amounts after CBP fermentation ( $p=0.60$ for low $\mathrm{S} / \mathrm{G}$ and $p=0.24$ for high S/G samples).

\section{Discussion}

Based on literature investigations, to our knowledge, the impact of the syringyl and guaiacyl content in various natural and synthetic substrates has been studied almost exclusively using free-enzyme systems. Microbial 
lignocellulose conversion quite often relies on adherent microbes that have improved access to substrates and in general show better hydrolytic performance than their purified cellulase preparations [28]. The objective of this study was to expand our comprehension of lignocellulose recalcitrance to microbial solubilization and in particular when the content of syringyl units is nearly equal to (low S/G ratio) or two-fold higher (high S/G ratio) than the guaiacyl monolignol content. The research presented here investigated a small sample size of a single-plant species, and represents a case study intended to identify key biomass properties that impact solubilization of biomass by microbes and purified enzymes. Further validation requires larger sample sets and/or multiple plant species.

Our initial screening of natural Populus variants showed $C$. thermocellum bioconversions could be just as sensitive to biomass compositional properties, and in particular with respect to lignin, as hydrolysis with commercial enzyme preparations [9]. Microbial hydrolysis of biomass in bioreactors showed a relative 50 \% improvement in solubilization for the unpretreated high S/G Populus compared the low S/G biomass. C. thermocellum bioconversion was comparable to the $52 \%$ relative difference in the glucose release from the hydrolysis of these plant lines with commercial enzyme blends, which indicate that the performance differentiator in microbial conversion is also likely at the level of enzymatic activity, rather than due to disparities in microbial growth. Surprisingly, both Populus samples had an average $15 \%$ relative reduction in total measured carbohydrates following microbial conversion, while glucan alone was reduced by $17-18 \%$ per gram of post-fermentation recovered solid, indicating that glucose extraction, or mining, from the lignocellulosic matrix did not occur preferentially in either Populus biomass. The limited solubilization in all tests is typical for the minimally processed (milled, washed, and autoclaved) woody biomass that was used to accentuate lignin differences without gross alterations $[29,30]$. Considering the large relative difference in total solid solubilization between these phenotypes, it is reasonable to conclude that microbial hydrolysis occurred in a similar mechanistic pattern, where the high S/G Populus was deconstructed at a faster rate. The evidence denotes less restricted enzyme access to the carbohydrates of the biomass with higher S/G lignin ratio; unfortunately, literature provides little corroboration on the actual mechanisms of complex lignocellulose breakdown by cellulolytic organisms.

A bias toward acetate production was observed in the fermentation of the low S/G Populus, and it is thought to be the consequence of lower carbon availability; a phenomenon also observed during the growth of this organism on pure cellulose substrates [31]. Previous reports cataloged the release of Populus-derived inhibitors against $C$. thermocellum after dilute acid pretreatment [32]; however, our fermentation metabolome analysis performed under the same GC-MS technique, did not reveal significant accumulation of these products which may be a result of using different biomass materials and/or different preparation methods. A previously unidentified component, $p$-hydroxybenzoic acid, was observed in this study but also found non-inhibitory when it alone was added in high levels. It remains uncertain if $p$-hydroxybenzoic acid is associated with lignin or hemicelluloses. Under the circumstances, differences in the activity of cell-bound enzymes could not be linked to the presence of aqueous inhibitors.

It was also important to compare the properties of cellulose and lignin in the two Populus samples that had been postulated in the literature to have a role in biomass solubilization, and to observe how these properties changed due to microbial activity. A lower cellulose degree of polymerization (DP) has been typically associated with greater availability of cellulose chain ends and therefore improved hydrolysis [21]. Our Populus phenotypes, exhibited cellulose of similar average chain length which marginally increased after fermentation, a phenomenon also observed in the utilization of birchwood by $C$. thermocellum [33]. In general, lower cellulose crystallinity improves hydrolysis with free-enzymes [22]. While cellulose accessibility can be affected by crystallinity, other attributes such as lignin/hemicellulose contents and distribution, porosity can play roles in cellulose digestibility [34], and the influence of crystallinity on consolidated bioprocessing with cellulolytic bacteria is less clear. Cellulose hydrolysis by $C$. thermocellum or its cellulosome has been proposed to occur at equal rates on crystalline and amorphous cellulose [33] and in other instances to occur rapidly on microcrystalline cellulose $[35,36]$. In the current study, cellulose crystallinity in the two Populus tested was not affected by lignin composition, and did not significantly change under CBP treatment. Crystallinity is not considered a performance differentiator in the solubilization of these Populus phenotypes.

Lignin molecular weight was the strongest indication of structural differences in the compared biomasses; where a low $\mathrm{S} / \mathrm{G}$ ratio resulted in greatly reduced lignin molecular weights. These results deviate from previous postulations that syringyl-rich lignins possess more fragmented structures and smaller molecular weights [9]. GPC separates polymers based on molecular size and assumes the polymer of interest to have spherical conformation in solution [37]; therefore, variations in calculated molecular weights may be attributed to differences 
in polymer chain size or conformation (i.e., a given polymer may appear low weight if it was highly branched, or high weight if it was straight chain). Hypothetically, structural disparities between lignins with low and high S/G ratios may stem from the radical polymerization of lignin. Coniferyl alcohol polymerization, which incorporates G-units into lignin, generates a more condensed lignin structure due to increased proportions of carboncarbon linkages [38]. The compact structure of lignin isolated from low S/G Populus may manifest itself as a lower molecular weight, whereas the less compact structure of the high $S / G$ phenotype may produce higher relative molecular weights.

Simon stains suggests the potential for greater enzyme accessibility to cellulose in samples with higher syringyl content [26], which points to higher surface porosity in the range of $5-36 \mathrm{~nm}$ and above. Although this may explain differences in enzymatic solubilization with free cellulases, this porosity range may not equally aid microbes with much larger footprints (i.e., micron size) which utilize complex, cell-bound cellulosome clusters. However, it remains to be determined whether the correlation between lignin composition and molecular size and the porosity of cellulose fibrils extends to future observations.

\section{Conclusions}

While microbial hydrolysis of unpretreated or minimally pretreated lignocellulosic substrates is considered more efficient than with cell-free enzyme mixtures, we found biomass properties to have equal impact on their capacity to solubilize celluloses and hemicelluloses. In particular, solubilization was greatly improved on the Populus phenotype with a higher ratio of syringyl-toguaiacyl lignin. The results found that the two significant properties of Populus tested in this study were cellulose accessibility and lignin molecular weight, both positively correlated to the $S / G$ ratio. We suggest that higher syringyl content leads to larger linear lignin chains, which present less interference for carbohydrate breakdown by free-enzymes and microbes.

\section{Methods}

\section{Microbial strains and culture media}

Clostridium thermocellum strain ATCC 27405 was maintained in $20 \%$ glycerol stock cultures at $-80{ }^{\circ} \mathrm{C}$. For batch bottle cultures, the strain was grown in defined MTC medium which was prepared anaerobically by mixing independently sterilized solutions. All medium components are reported here at final complete medium concentrations, per liter of ultrapure water. Initially, solution A (2.5 or 10 g Avicel PH-101, 0.001 g Resazurin) was sterilized by autoclave. Solution D (1 g magnesium chloride hexahydrate, $0.2 \mathrm{~g}$ calcium chloride dehydrate, $0.1 \mathrm{~g}$ ferrous chloride tetrahydrate, $1 \mathrm{~g}$ L-cysteine hydrochloride monohydrate) was also prepared fresh for each set of experiments and sterilized by autoclave. The remaining solutions, sterilized by filtration on $0.2 \mu \mathrm{m}$ filters, contained the following: solution B $+\mathrm{M}$ (2 g potassium citrate, $1.25 \mathrm{~g}$ citric acid monohydrate, $1 \mathrm{~g}$ sodium sulfate dibasic, $1 \mathrm{~g}$ potassium phosphate monobasic, $2.5 \mathrm{~g}$ sodium bicarbonate, $5 \mathrm{~g}$ MOPS hemisodium salt), solution C (1.5 g ammonium chloride, $2 \mathrm{~g}$ urea), solution $\mathrm{E}$ (20 mg pyridoxamine dihydrochloride, $1 \mathrm{mg}$ riboflavin, $1 \mathrm{mg}$ nicotinamide, $0.5 \mathrm{mg}$ lipoic acid, $4 \mathrm{mg} 4$-aminobenzoic acid, $4 \mathrm{mg}$ D-biotin, $0.025 \mathrm{mg}$ folic acid, $2 \mathrm{mg}$ cyanocobalamin, $0.2 \mathrm{mg}$ thiamine hydrochloride), and solution F (0.5 mg manganese chloride tetrahydrate, $0.5 \mathrm{mg}$ cobalt chloride hexahydrate, $0.2 \mathrm{mg}$ zinc sulfate heptahydrate, $0.05 \mathrm{mg}$ copper sulfate pentahydrate, 0.05 boric acid, $0.05 \mathrm{mg}$ sodium molybdenum oxide dihydrate, $0.05 \mathrm{mg}$ nickel chloride hexahydrate, $10 \mathrm{mg}$ citric acid monohydrate). Filter sterilized solutions $(B+M, C$, E, F) can be prepared as concentrated stocks $(25 \times, 50 \times$, $50 \times$, and $1000 \times$, respectively). Medium composition for $\mathrm{pH}$-controlled batch bioreactor cultures was similar, with the replacement in solution A of Avicel with Populus biomass $(20 \mathrm{~g} / \mathrm{L}$ on a dry basis) and the omission of MOPS hemisodium salt from solution $B+M$.

Saccharomyces cerevisiae D5A (ATCC 200062) was maintained on YPD (10 g/L yeast extract, $20 \mathrm{~g} / \mathrm{L}$ peptone, and $10 \mathrm{~g} / \mathrm{L}$ glucose, $20 \mathrm{~g} / \mathrm{L}$ agar) plates, and the same broth medium was used for overnight growth.

\section{Populus biomass preparation and compositional analysis} Four-year old tree of Populus genotypes BESC-102 and HARA-26-2 was harvested from a field site in Clatskanie, OR $\left(46^{\circ} 6^{\prime} 11^{\prime \prime} \mathrm{N} 123^{\circ} 12^{\prime} 13^{\prime \prime} \mathrm{W}\right)$. Details of field establishment, growth conditions, and post-harvest handling were previously described by Muchero et al. [39].

Populus stem sections were milled (Mini Wiley Mill, Thomas Scientific, Swedesboro, NJ, USA), size selected using a 20 -mesh screen (i.e., maximum $0.84 \mathrm{~mm}$ particle size), and autoclaved at $121{ }^{\circ} \mathrm{C}$ for $20 \mathrm{~min}$ at $20 \mathrm{~g} / \mathrm{L}$ concentration. The biomass was then washed with $1 \mathrm{~L}$ of ultrapure water for every $10 \mathrm{~g}$ solids. Washed biomass was then used in the preparation of solution A in batch bottle and bioreactor media where it was loaded wet, but on a dry basis, based on previously determined dry-towet weight ratios and autoclaved for a second time during the sterilization of solution A in medium preparation steps. Carbohydrate content in washed biomass did not change significantly (Additional file 1: Figure A.3); total lignin content decreased slightly (possibly due to washout of very small wood particulates) while S/G ratios did not change (Additional file 1: Figure A.4). The purpose 
of autoclave-washing was to reduce the presence of foreign particulates, kill contaminants, and remove loosely bound inhibitors. It was determined that the washing step did not significantly impact biomass solubilization assays (i.e., washed biomass only showed an extra $1 \%$ better solubilization than unwashed Populus in our SHF controls-data not shown).

Carbohydrate content in fresh and post-fermentation biomass solids was determined by quantitative saccharification assay NREL/TP-510-42618 and HPLC method NREL/TP-510-42623. In short, biomass carbohydrates were acid hydrolyzed in $72 \% \mathrm{w} / \mathrm{w} \mathrm{H}_{2} \mathrm{SO}_{4}$ (0.1 g solids/ $\mathrm{mL}$ acid) for $1 \mathrm{~h}$ at $30{ }^{\circ} \mathrm{C}$, followed by further oligomer breakdown in $4 \% \mathrm{w} / \mathrm{w} \mathrm{H}_{2} \mathrm{SO}_{4}$ at $121{ }^{\circ} \mathrm{C}$ for $1 \mathrm{~h}$. Samples were then neutralized to $\mathrm{pH} \sim 7$ with calcium carbonate and $0.2 \mu \mathrm{m}$ filtered before carbohydrate content (glucose, xylose, galactose, mannose, and arabinose) quantification by high performance liquid chromatography (LaChrom Elite ${ }^{\mathrm{TM}}$, Hitachi High Technologies America Inc.) against known standards. HPLC product separation was done using an Aminex ${ }^{\mathrm{TM}}$ HPX-87P column (BioRad Laboratories Inc., Hercules, CA) at $0.6 \mathrm{~mL} / \mathrm{min}$ flow rate of ultrapure water and column temperature of $80^{\circ} \mathrm{C}$; while signal was quantified on a refractive index detector (model L-2490) at $35^{\circ} \mathrm{C}$. Pentose and hexose degradation products (furfural and 5-hydroxymethyl furfural, respectively) were also quantified (UV-Vis L-2420 detector) to confirm optimum acid solubilization with only trace amounts of monomeric sugar breakdown. Total lignin content and the $S / G$ ratio were determined by pyrolysis molecular beam mass spectrometry with methods previously described [40]. Total lignin content determinations in washed biomass which are normalized to gram solids may have underestimated the true values due to insufficiently dried biomass. We show that relative lignin content remained comparable between low S/G and high S/G biomasses.

\section{Consolidated bioprocessing (CBP): culturing conditions and fermentation product quantification}

Media bottles for small-scale CBP screenings (at $50 \mathrm{~mL}$ culture volume) were prepared to anaerobic conditions by autoclave sterilization of solution A followed by vigorous sparging with nitrogen gas, followed by the sterile addition of all other components in aliquots from prefiltered stocks. The final mixtures were sparged with nitrogen once again, for a minimum of $20 \mathrm{~min}$. Inocula were prepared by starting an overnight culture in $2.5 \mathrm{~g} / \mathrm{L}$ Avicel-MTC medium from glycerol-stocks and then transferring a $20 \% \mathrm{v} / \mathrm{v}$ aliquot of growing culture to a fresh $2.5 \mathrm{~g} / \mathrm{L}$ Avicel-MTC bottle for a second overnight growth phase. This process ensured a uniform and fastgrowing inoculum source for all CBP-based experiments.
All CBP-based experiments, in batch bottles or pH-controlled bioreactors were carried out in triplicate for each tested biomass substrate. The inoculation of bottles and bioreactors was always made with $10 \% \mathrm{v} / \mathrm{v}$ freshly grown cultures.

\section{CBP conversion screening of initial four Populus phenotypes}

C. thermocellum was grown in batch bottles with $5 \mathrm{~g} / \mathrm{L}$ Populus biomass (dry basis) for $96 \mathrm{~h}$ at $60^{\circ} \mathrm{C}$ with moderate shaking (150 rpm in MaxQ 6000, Thermo Scientific, Marietta, $\mathrm{OH})$. At $24 \mathrm{~h}$ intervals, the bottles were vented with a syringe needle for $20 \mathrm{~s}$ inside an anaerobic cabinet (Coy Laboratories Products Inc., Grass Lake, MI) and the weight was recorded. The loss in weight due to release of fermentation gases was plotted over time and used as an indicator of overall bioconversion progress and has been used previously [41]. End-point aqueous samples were collected for fermentation product quantification by HPLC.

\section{CBP of low S/G and high S/G Populus in $\mathrm{pH}$-controlled bioreactors}

Microbial bioconversions were performed in 1 liter Sartorius BIOSTAT QPlus bioreactors (Sartorius Stedim Biotech, Göttingen, Germany), operated at $60{ }^{\circ} \mathrm{C}, \mathrm{pH} 7$ (titrated with $3 \mathrm{~N} \mathrm{KOH}$ ), and $200 \mathrm{rpm}$ impeller mixing. Media were prepared in bioreactors at a final volume of 0.4 liters by autoclave sterilization of solution A (containing $20 \mathrm{~g} / \mathrm{L}$ Populus biomass or $10 \mathrm{~g}$ Avicel), followed by cooling under continuous nitrogen sparging for $18 \mathrm{~h}$. Medium components B, C, D, E, and F were then added to the reactors under sterile conditions and the $\mathrm{pH}$ probe was recalibrated. A mixture of $20 \% \mathrm{CO}_{2} / 80 \% \mathrm{~N}_{2}$ gas was sparged through the reactors until the media $\mathrm{pH}$ reached 6; gas sparging was then switched to nitrogen for the duration of the experiment (at $0.4 \mathrm{~mL} / \mathrm{min}$ mass flow rate) and the $\mathrm{pH}$ was raised and maintained to 7 with base addition before finally adding aliquots of fresh inoculum (at $10 \% \mathrm{v} / \mathrm{v})$. At regular intervals, solids-free aqueous samples were collected and analyzed for monomeric sugars and fermentation products by HPLC. Fermentation gases passed through a $4{ }^{\circ} \mathrm{C}$ cooled condenser and a water bubble trap where traces of fermented ethanol and organic acids were also detected and quantified at the end of experiment. Water trap ethanol accounted for up to $5 \%$ of the total fermentation ethanol and was not included in further calculations (as reported in Fig. 3).

HPLC analysis of all hydrolysis and fermentation samples used a similar method to the carbohydrate quantification. Samples were $0.2 \mu \mathrm{m}$ filtered and acidified to $\mathrm{pH}$ 2 with $2 \mathrm{M} \mathrm{H}_{2} \mathrm{SO}_{4}$ and the products were separated using an Aminex HPX-87H column (Bio-Rad Laboratories Inc., 
Hercules, CA) at $60{ }^{\circ} \mathrm{C}$, at a flow rate of $0.5 \mathrm{~mL} / \mathrm{min}$ with $5.0 \mathrm{mM} \mathrm{H}_{2} \mathrm{SO}_{4}$ mobile phase. Separated products were detected by refractive index (detector model L-2490 at $50{ }^{\circ} \mathrm{C}$ ) and quantified against known standards.

Total solids solubilization at the end of CBP fermentations was calculated by determining the dry weight of residual solids. In short, $50 \mathrm{~mL}$ of well-mixed culture medium with biomass residues was collected and filtered through glass microfibre filters (Whatman GF/D, $47 \mathrm{~mm}$ diameter, GE Healthcare Life Sciences, Buckinghamshire, UK), then dried overnight at $45^{\circ} \mathrm{C}$.

\section{Determination of sugar release via free-enzyme hydrolysis and yeast-based ethanol production}

Separate hydrolysis and fermentation (SHF) of low and high S/G Populus samples was done in batch bottles with a $5.0 \%(\mathrm{w} / \mathrm{v})$ solids loading in a $20 \mathrm{~mL}$ final volume. In the initial hydrolysis step, the biomass, enzymes, $0.05 \mathrm{~mL}$ streptomycin $(0.063 \mathrm{mg} / \mathrm{ml}$ final concentration), and $16 \mathrm{~mL}$ of ultrapure water were mixed and incubated with gentle shaking at $50{ }^{\circ} \mathrm{C}$ for 5 days. Cellulase mix Cellic ${ }^{\circledR}$ Ctec2 was loaded at $24 \mathrm{FPU} / \mathrm{g}$ cellulose, while the $\beta$-glucosidase Novozymes 188 and hemicellulases Cellic ${ }^{\circledR}$ Htec2 were loaded at 25 and $20 \%$ volume ratios to Ctec2. Novozymes 188 was purchased from Sigma Aldrich and other enzymes were donated by Novozymes North America (Franklinton, NC). Sugar-release aqueous samples were collected at the end of hydrolysis and the bottles inoculated with a mixture of exponential growth Saccharomyces cerevisiae D5A (ATCC 200062), citrate buffer (50 mM final concentration), and yeast extract $(0.5 \% \mathrm{w} / \mathrm{v}$ final concentration). Sugar fermentation continued at $35^{\circ} \mathrm{C}$ for 3 days with mixing, and weight loss measurements were taken at regular intervals to monitor progress. Fermentation ethanol yield was determined at end-point by HPLC quantification with the same procedure described for CBP.

\section{Identification of potential biomass-derived inhibitors in the CBP fermentation metabolome}

CBP fermentation samples of the low S/G and high S/G Populus, collected post-inoculation $(0 \mathrm{~h})$, during exponential growth $(71 \mathrm{~h})$ and at end-point $(140 \mathrm{~h})$, were analyzed for the presence of potential microbial inhibitors by gas chromatography-mass spectrometry (GC-MS) using previously described methods [32].

\section{Screening the inhibitory effect of $p$-hydroxybenzoic acid}

Media batch bottles prepared with $20 \mathrm{~g} / \mathrm{L}$ biomass of the high S/G Populus were supplemented with $p$-hydroxybenzoic acid at 4 and $40 \mathrm{mg} / \mathrm{L}$ final concentrations, inoculated with $C$. thermocellum cultures and incubated at $60{ }^{\circ} \mathrm{C}$ for $120 \mathrm{~h}$. At regular intervals, aqueous aliquots were collected and analyzed by HPLC for fermentation products. Cultures without $p$-hydroxybenzoic acid additions and un-inoculated media controls were used as well.

\section{Lignin and cellulose characterization}

Starting biomass and the recovered CBP post-fermentation solids were frozen at $-80{ }^{\circ} \mathrm{C}$ and freeze-dried to remove moisture. Extractives were removed from the biomass via Soxhlet extraction with dichloromethane for $4.5 \mathrm{~h}$ under reflux and the extractive-free samples were air-dried overnight prior to further sample preparation.

\section{Molecular weight of lignin}

The freeze-dried biomass was ball-milled to a fine powder at $520 \mathrm{rpm}$ for $90 \mathrm{~min}$. Samples of $300 \mathrm{mg}$ were hydrolyzed in stoppered glass tubes with $20 \mathrm{~mL}$ of an enzyme cocktail containing cellulases from Trichoderma sp. (C1794, Sigma Aldrich, St. Louis, MO), cellulases from Trichoderma reesei ATCC 26921 (C2730, Sigma Aldrich, St. Louis, MO), and a $\beta$-glucosidase from almonds (G0395, Sigma Aldrich, St. Louis, MO) that had been pre-mixed in $20 \mathrm{mM}$ sodium acetate buffer $(\mathrm{pH}$ 5.0). After incubation with shaking $(200 \mathrm{rpm})$ at $37^{\circ} \mathrm{C}$ for $48 \mathrm{~h}$, the tubes were centrifuged at $8228 \times g(8000 \mathrm{rpm})$ for $10 \mathrm{~min}$, and the supernatant was discarded. A new batch $(20 \mathrm{~mL})$ of the enzyme mixture was prepared and added to the pellet. Incubation resumed for an additional $48 \mathrm{~h}$ and the supernatant was discarded again. The pellet was washed twice with deionized water, frozen, and freeze-dried. In order to isolate lignin, $p$-dioxane $(96 \%$ $\mathrm{v} / \mathrm{v}$ ) was added to the dry pellet at $10 \mathrm{~mL} / \mathrm{g}$ biomass and the mixture was stirred at room temperature for $24 \mathrm{~h}$. The mixture was then centrifuged, the supernatant collected, and the remaining solids were treated with $p$-dioxane $(96 \% \mathrm{v} / \mathrm{v})$ again under the same conditions. Supernatants from both extractions were combined, $p$-dioxane was evaporated using rotary evaporator, and freeze-dried to recover the isolated lignin. Lignin was derivatized by mixing $10 \mathrm{mg}$ of isolated product with $1 \mathrm{~mL}$ of $1: 1$ anhydrous pyridine/acetic anhydride for $24 \mathrm{~h}$ at room temperature, and the reaction mixture was quenched with $5 \mathrm{~mL}$ ethanol. Derivatized lignin was washed several times with ethanol via rotary evaporation to remove residual chemicals and vacuum-dried. It was then dissolved in tetrahydrofuran (THF) (at $2 \mathrm{mg} / \mathrm{mL}$ ), and filtered through $0.45 \mu \mathrm{m}$ PTFE membrane. Molecular weight analysis was conducted by gel permeation chromatography (SECurity GPC 1200 System, Polymer Standards Services, Warwick, RI) containing four Waters Styragel columns (HR1, HR2, HR4, and HR6), an Agilent refractive index detector, an Agilent UV-detector (Agilent Technologies, Santa Clara, CA) with a THF mobile phase at $1 \mathrm{~mL} / \mathrm{min}$ flow rate. The molecular weights of lignin were calculated against 
polystyrene standards in the $0.58 \times 10^{3}$ to $5.38 \times 10^{5} \mathrm{~g} /$ mol range.

\section{Degree of polymerization of a-cellulose}

Freeze-dried biomass was delignified by treatment of $0.6 \mathrm{~g}$ samples with $5 \% \mathrm{w} / \mathrm{w}$ peracetic acid for $24 \mathrm{~h}$ at $25{ }^{\circ} \mathrm{C}$, then washed by water filtration several times and air-dried overnight. Hemicellulose was removed by solubilization in $17.5 \% \mathrm{w} / \mathrm{w} \mathrm{NaOH}$ for $2 \mathrm{~h}$ and $8.75 \% \mathrm{w} / \mathrm{w}$ $\mathrm{NaOH}$ for an additional $2 \mathrm{~h}$, and the insoluble cellulose was recovered and cleaned by filtration and washing with $1 \% \mathrm{w} / \mathrm{w}$ acetic acid and ultrapure water several times. The cellulose was frozen, freeze-dried overnight, and vacuum-dried for an additional night. It was then derivatized using anhydrous pyridine $(4 \mathrm{~mL})$ and phenyl isocyanate $(0.5 \mathrm{~mL})$ over 3 days at $55{ }^{\circ} \mathrm{C}$, and the reaction was quenched with methanol. The derivatized cellulose was regenerated in 7:3 methanol/water and then purified by repeat centrifugation at $8228 \times g(8000 \mathrm{rpm})$ for $10 \mathrm{~min}$ with resuspension in methanol/water and twice in water alone. The tricarbanilated cellulose was vacuum-dried overnight, then dissolved overnight in THF $(1: 1 \mathrm{mg} /$ $\mathrm{mL}$ ), and the solution was filtered using a $0.45-\mu \mathrm{m}$ PTFE syringe filter. Cellulose molecular weight was determined by gel permeation chromatography against polystyrene standards, with a $1-\mathrm{mL} / \mathrm{min}$ flow rate of the THF mobile phase. The degree of polymerization (DP) was calculated as the fraction of the number-average molecular weight $\left(M_{\mathrm{n}}\right)$ or the weight-average molecular weight $\left(M_{\mathrm{w}}\right)$ to $519 \mathrm{~g} / \mathrm{mol}$.

\section{Cellulose crystallinity}

Hemicellulose was hydrolyzed from $300 \mathrm{mg}$ holocellulose (obtained through delignification, as described above) through reflux with $2.5 \mathrm{M} \mathrm{HCl}$ for $90 \mathrm{~min}$ and the recovered cellulose washed several times with ultrapure water by filtration. Cellulose crystallinity in moist samples was calculated from the attenuated total reflectanceFourier transform infrared (ATR-FTIR) spectra obtained at $4 \mathrm{~cm}^{-1}$ resolution with 64 scans on the PerkinElmer Spectrum 100 FTIR spectrometer (PerkinElmer, Houston, TX) equipped with a universal crystal ATR accessory [42].

In conjunction with ATR-FTIR analysis, cellulose crystallinity was determined with ${ }^{13} \mathrm{C}$ cross-polarization magic-angle spinning (CP-MAS) NMR spectroscopy. The acid-hydrolyzed cellulose was packed into $4 \mathrm{~mm}$ cylindrical ceramic MAS rotors analyzed on the Bruker DSX-400 NMR spectrometer (Bruker, Billerica, MA, United States) at an operating frequency of $100.55 \mathrm{MHz}$ in a Bruker double-resonance MAS probe head. The CP-MAS experiments were conducted with the following parameters: 2024 scans, $1.5 \mathrm{~ms}$ contact pulse, $4 \mathrm{~s}$ recycle delay, and a $5 \mu \mathrm{s}\left(90^{\circ}\right)$ pulse. Additionally, each sample was spun at $8 \mathrm{kHz}$ [43].

In the resulting spectra, $\mathrm{C} 4$ in cellulose is split into two peaks that correspond to the crystalline and amorphous character of cellulose. The "amorphous" peak lies between 80 and $86 \mathrm{ppm}$, while the "cellulose" peak lies between 86 and $92 \mathrm{ppm}$. The crystallinity index (CrI) of cellulose can be calculated from the areas of the peaks between 80-86 ppm $\left(A_{80-86 \mathrm{ppm}}\right)$ and $86-92 \mathrm{ppm}\left(A_{86-92 \mathrm{ppm}}\right)$, as indicated in Eq. 1.

$$
\mathrm{CrI}(\%)=\frac{A_{86-92 \mathrm{ppm}}}{A_{80-86 \mathrm{ppm}}+A_{86-92 \mathrm{ppm}}} \times 100 .
$$

\section{Cellulose accessibility by Simons' staining}

Direct Blue 1 (Pontamine Fast Sky Blue 6BX) and Direct Orange 15 (Pontamine Fast Orange 6RN) were obtained from Pylam Products Co. Inc. (Garden City, NY) and used at a working concentration of $10 \mathrm{mg} / \mathrm{mL}$ in water. For Direct Orange 15, the low molecular weight components were first removed by ultrafiltration through $100 \mathrm{~K}$ membranes with $\sim 200 \mathrm{kPa}$ nitrogen gas (Amicon stirred cell, EMD Millipore Corp., Billerica, MA) - as this fraction demonstrated similar cellulose affinity with Direct Blue 1 [44]. The residual weight of filter-trapped dye was used to estimate the effective Direct Orange concentration in the filtrate and the stain was then further diluted to the working concentration. The dye mix adsorption isotherm was determined using a series of 1:1 mixtures with increasing concentrations.

Fresh and post-fermentation Populus samples $(\sim 10 \mathrm{mg})$ were suspended in $0.1 \mathrm{~mL}$ buffered saline solution $\left(0.3 \mathrm{M} \mathrm{Na}_{3} \mathrm{PO}_{4}\right.$ and $1.4 \mathrm{mM} \mathrm{NaCl}$ at $\left.\mathrm{pH} 6\right)$ and the volume was adjusted to $1.0 \mathrm{ml}$ with deionized water. The samples were incubated with shaking at $70{ }^{\circ} \mathrm{C}$ for $6 \mathrm{~h}$, then centrifuged at $10,252 \times g(10,000 \mathrm{rpm})$ for $5 \mathrm{~min}$, and the supernatant was collected. Supernatant absorbance was measured using the Lambda 35 UV-Vis Spectrophotometer (PerkinElmer, Waltham, MA), and the calculations for analysis were adapted from Chandra et al. [45]

\section{Statistical analysis}

The modified $z$-score, proposed by Iglewicz and Hoaglin, was used to detect outliers in this study due to its relevancy to small sample sizes. The modified $z$-score $\left(M_{\mathrm{i}}\right)$ was calculated for each datum using Eq. 2. Any datum possessing a modified $z$-score $\geq 3.5$ was labeled as a potential outlier and removed from further analysis.

$$
\begin{aligned}
& M_{\mathrm{i}}=\frac{0.6745\left(x_{\mathrm{i}}-\tilde{x}\right)}{\operatorname{MAD}}, \\
& \quad \text { where MAD }=\operatorname{median}\left(\left|Y_{\mathrm{i}}-\tilde{Y}\right|\right),
\end{aligned}
$$


where appropriate, samples means were compared using a two-sample $t$ test and the $p$ value was calculated with equal or different variances based on the results of a previously run $F$ test. Origin Pro software was used for the calculations, and the $p$ value represented the probability that observed differences between means was due to random chance (i.e., when $p<0.05$ the probability for random chance is very small, and the means are considered statistically different).

\section{Additional file}

Additional file 1: Figure A.1. Carbohydrate composition of initially screened Populus biomass. Figure A.2. Fermentation products of Avicelcontrol CBP cultures. Figure A.3. Carbohydrate content in Populus before and after repeat autoclave sterilization. Figure A.4. Lignin content in Populus before and after repeat autoclave sterilization.

\section{Abbreviations}

ATR-FTIR: attenuated total reflectance-Fourier transform infrared; CBP: consolidated bioprocessing; DP: degree of polymerization; FPU: filter paper units; GC-MS: gas chromatography-mass spectrometry; GPS: gel permeation chromatography; HPLC: high pressure liquid chromatography; $M_{w}$ : weight-average molecular weight; $M_{\mathrm{n}}$ : number-average molecular weight; $S / G$ : syringyl-toguaiacyl ratio; SHF: separate hydrolysis and fermentation.

\section{Authors' contributions}

$A D, B H D, A R$, and SDB designed the study and prepared the manuscript. AD drafted the manuscript, performed bioconversions, feedstock preparations, carbohydrate content assays, and HPLC analysis. HA performed cellulose DP and crystallinity analysis, and contributed to study design and manuscript preparation. MJR assisted in the study design and edited the manuscript, assisted with bioconversions, feedstock preparations, carbohydrate assays, and HPLC. XM performed Simons' staining and helped writing the associated sections. CGY performed lignin molecular weight analysis. JN helped with experiment planning, manuscript drafting, and performed carbohydrate assays and HPLC. NLE performed GC-MS analysis for inhibitor detection. RWS performed pyrolysis molecular beam-MS for total lignin and S/G quantification. TJT contributed to study design and interpretations of inhibitor release. WM provided the Populus biomass and contributed to study design. All authors have read and approved the final manuscript.

\begin{abstract}
Author details
${ }^{1}$ Biosciences Division, Oak Ridge National Laboratory, Oak Ridge, TN 37831 , USA. ${ }^{2}$ BioEnergy Sciences Center, Bioscience Division, Oak Ridge National Laboratory, Oak Ridge, TN 37830, USA. ${ }^{3}$ Renewable Bioproducts Institute, Georgia Institute of Technology, Atlanta, GA 30332, USA. ${ }^{4}$ UT-ORNL Joint Institute for Biological Sciences, Oak Ridge National Laboratory, Oak Ridge, TN 37831 , USA. ${ }^{5}$ School of Chemistry and Biochemistry, Georgia Institute of Technology, Atlanta, GA 30332, USA. ${ }^{6}$ National Renewable Energy Laboratory, US Department of Energy, Golden, CO 80401, USA. ${ }^{7}$ Department of Chemical and Biomolecular Engineering, Department of Forestry, Wildlife, and Fisheries, University of Tennessee, Knoxville, TN 37996, USA.
\end{abstract}

\section{Acknowledgements}

We thank Kelsey L. Yee (Genomatica Inc., CA) for discussions on lignin while she was at ORNL. We also thank Holly M. Vander Stel (ORNL) for assistance in the preparation of lignin samples. This manuscript has been authored by UT-Battelle, LLC under Contract No. DE-AC05-00OR22725 with the U.S. Department of Energy. The United States Government retains and the publisher, by accepting the article for publication, acknowledges that the United States Government retains a non-exclusive, paid-up, irrevocable, world-wide license to publish or reproduce the published form of this manuscript, or allow others to do so, for United States Government purposes. The Department of Energy will provide public access to these results of federally sponsored research in accordance with the DOE Public Access Plan (http://energy.gov/downloads/ doe-public-access-plan). This research was funded by the Bioenergy Science Center (BESC) which is a U.S. Department of Energy Bioenergy Research Center supported by the Office of Biological and Environmental Research in the DOE Office of Science. ORNL is managed by UT-Battelle, LLC, Oak Ridge, TN, USA, for the DOE under contract DE-AC05-00OR22725.

\section{Competing interests}

The authors declare that they have no competing interests.

Received: 5 November 2015 Accepted: 20 January 2016

Published online: 04 February 2016

\section{References}

1. Basen M, Rhaesa AM, Kataeva I, Prybol CJ, Scott IM, Poole FL, Adams MWW. Degradation of high loads of crystalline cellulose and of unpretreated plant biomass by the thermophilic bacterium Caldicellulosiruptor bescii. Bioresour Technol. 2014;152:384-92.

2. Fu C, Mielenz JR, Xiao X, Ge Y, Hamilton CY, Rodriguez M, Chen F, Foston M, Ragauskas A, Bouton J, Dixon Ra, Wang Z-Y. Genetic manipulation of lignin reduces recalcitrance and improves ethanol production from switchgrass. Proc Natl Acad Sci U S A. 2011;108:3803-8.

3. Yee KL, Rodriguez M, Tschaplinski TJ, Engle NL, Martin MZ, Fu C, Wang Z-Y, Hamilton-Brehm SD, Mielenz JR. Evaluation of the bioconversion of genetically modified switchgrass using simultaneous saccharification and fermentation and a consolidated bioprocessing approach. Biotechnol Biofuels. 2012;5:81.

4. Lynd LR, Weimer PJ, van ZyI WH, Pretorius IS. Microbial cellulose utilization: fundamentals and biotechnology. Microbiol Mol Biol Rev. 2002;66:506-77.

5. Papanek B, Biswas R, RydzakT, Guss AM: Elimination of metabolic pathways to all traditional fermentation products increases ethanol yields in Clostridium thermocellum. Metab Eng. 2015;32:49-54.

6. Porth I, El-Kassaby YA. Using Populus as a lignocellulosic feedstock for bioethanol. Biotechnol J. 2015;10:510-24.

7. Cheng J, Yu Y, Zhu M. Enhanced biodegradation of sugarcane bagasse by Clostridium thermocellum with surfactant addition. Green Chem. 2014;16:2689-95.

8. Yu Z, Gwak K-S, Treasure T, Jameel H, Chang H, Park S. Effect of lignin chemistry on the enzymatic hydrolysis of woody biomass. ChemSusChem. 2014;7:1942-50.

9. Studer MH, DeMartini JD, Davis MF, Sykes RW, Davison B, Keller M, Tuskan GA, Wyman CE. Lignin content in natural Populus variants affects sugar release. Proc Natl Acad Sci USA. 2011;108:6300-5.

10. Santos RB, Capanema Ea, Balakshin MY, Chang HM, Jameel H. Lignin structural variation in hardwood species. J Agric Food Chem. 2012;60:4923-30.

11. Kishimoto T, Chiba W, Saito K, Fukushima K, Uraki Y, Ubukata M. Influence of syringyl to guaiacyl ratio on the structure of natural and synthetic lignins. J Agric Food Chem. 2010;58:895-901.

12. Jung $H G$, Deetz DA. Cell wall lignification and degradability. In: Jung $H G$, Buxton DR, Hatfield RD, Ralph J, editors. Forage cell wall structure and digestibility. Madison, WI: ASA-CSSA-SSSA; 1993. p. 315-346.

13. Davison BH, Drescher SR, Tuskan GA, Davis MF, Nghiem NP. Variation of S/G ratio and lignin content in a Populus family influences the release of xylose by dilute acid hydrolysis. Appl Biochem Biotechnol. 2006;129-132:427-35.

14. Van Acker R, Leplé J-C, Aerts D, Storme V, Goeminne G, Ivens B, Légée F, Lapierre C, Piens K, Van Montagu MCE, Santoro N, Foster CE, Ralph J, Soetaert W, Pilate G, Boerjan W. Improved saccharification and ethanol yield from field-grown transgenic poplar deficient in cinnamoyl-CoA reductase. Proc Natl Acad Sci USA. 2014;111:845-50.

15. Chen F, Dixon RA. Lignin modification improves fermentable sugar yields for biofuel production. Nat Biotechnol. 2007;25:759-61.

16. Grabber JH, Ralph J, Hatfield RD. p-Hydroxyphenyl, guaiacyl, and syringy lignins have similar inhibitory effects on wall degradability. J Agric Food Chem. 1997:45(2):2530-2. 
17. Li X, Ximenes E, Kim Y, Slininger M, Meilan R, Ladisch M, Chapple C. Lignin monomer composition affects Arabidopsis cell-wall degradability after liquid hot water pretreatment. Biotechnol Biofuels. 2010;3:27.

18. Fontaine AS, Bout $S$, Barrière $Y$, Vermerris W. Variation in cell wall composition among forage maize (Zea mays L.) inbred lines and its impact on digestibility: analysis of neutral detergent fiber composition by pyrolysis-gas chromatography-mass spectrometry. J Agric Food Chem. 2003;51:8080-7.

19. Skyba O, Douglas CJ, Mansfield SD. Syringyl-rich lignin renders poplars more resistant to degradation by wood decay fungi. Appl Environ Microbiol. 2013;79:2560-71.

20. Huntley SK, Ellis D, Gilbert M, Chapple C, Mansfield SD. Significant increases in pulping efficiency in $\mathrm{C} 4 \mathrm{H}-\mathrm{F} 5 \mathrm{H}$-transformed poplars: improved chemical savings and reduced environmental toxins. J Agric Food Chem. 2003;51:6178-83.

21. Hallac BB, Ragauskas AJ. Analyzing cellulose degree of polymerization and its relevancy to cellulosic ethanol. Biofuels Bioprod Biorefin. 2012;6:246-56.

22. Hall M, Bansal P, Lee JH, Realff MJ, Bommarius AS. Cellulose crystallinity - a key predictor of the enzymatic hydrolysis rate. FEBS J. 2010;277:1571-82.

23. Dehghani M, Karimi K, Sadeghi M. Pretreatment of rice straw for the improvement of biogas production. Energy Fuels. 2015;29:3770-5.

24. Monlau F, Aemig Q, Barakat A, Steyer J-P, Carrère H. Application of optimized alkaline pretreatment for enhancing the anaerobic digestion of different sunflower stalks varieties. Environ Technol. 2013;34:2155-62.

25. Sannigrahi P, Ragauskas AJ, Tuskan GA. Poplar as a feedstock for biofuels: a review of compositional characteristics. Biofuels Bioprod Biorefin. 2010;4:209-26.

26. Inglesby M, Zeronian S. Direct dyes as molecular sensors to characterize cellulose substrates. Cellulose. 2002;9:19-29.

27. Chandra RP, Saddler JN. Use of the Simons'staining technique to assess cellulose accessibility in pretreated substrates. Ind Biotechnol. 2012;8:230-7.

28. Lu Y, Zhang Y-HP, Lynd LR. Enzyme-microbe synergy during cellulose hydrolysis by Clostridium thermocellum. Proc Natl Acad Sci USA. 2006;103:16165-9.

29. Akinosho H, Yee K, Close D, Ragauskas A. The emergence of Clostridium thermocellum as a high utility candidate for consolidated bioprocessing applications. Front Chem. 2014;2:66

30. Yee KL, Rodriguez M, Thompson Oa, Fu C, Wang Z-Y, Davison BH, Mielenz JR. Consolidated bioprocessing of transgenic switchgrass by an engineered and evolved Clostridium thermocellum strain. Biotechnol Biofuels. 2014;7:75.

31. Islam R, Cicek N, Sparling R, Levin D. Influence of initial cellulose concentration on the carbon flow distribution during batch fermentation by Clostridium thermocellum ATCC 27405. Appl Microbiol Biotechnol. 2009:82:141-8.

32. Linville JL, Rodriguez M, Land M, Syed MH, Engle NL, Tschaplinski TJ, Mielenz JR, Cox CD. Industrial robustness: understanding the mechanism of tolerance for the Populus hydrolysate-tolerant mutant strain of Clostridium thermocellum. PLOS ONE. 2013;8:1-16.
33. Puls J, Wood TM. The degradation pattern of cellulose by extracellular cellulases of aerobic and anaerobic microorganisms. Bioresour Technol. 1991;36:15-9.

34. Park S, Baker JO, Himmel ME, Parilla PA, Johnson DK. Cellulose crystallinity index: measurement techniques and their impact on interpreting cellulase performance. Biotechnol Biofuels. 2010;3:10.

35. Shao X, Jin M, Guseva A, Liu C, Balan V, Hogsett D, Dale BE, Lynd L. Conversion for Avicel and AFEX pretreated corn stover by Clostridium thermocellum and simultaneous saccharification and fermentation: insights into microbial conversion of pretreated cellulosic biomass. Bioresour Technol. 2011;102:8040-5.

36. Resch MG, Donohoe BS, Ciesielski PN, Nill JE, Magnusson L, Himmel ME, Mittal A, Katahira R, Biddy MJ, Beckham GT. Clean fractionation pretreatment reduces enzyme loadings for biomass saccharification and reveals the mechanism of free and cellulosomal enzyme synergy. ACS Sustain Chem Eng. 2014;2:1377-87.

37. Mori S, Barth HG. Size exclusion chromatography. Berlin: Springer Science \& Business Media; 2013.

38. Wagner A, Tobimatsu Y, Phillips L, Flint H, Geddes B, Lu F, Ralph J. Syringyl lignin production in conifers: proof of concept in a pine tracheary element system. Proc Natl Acad Sci. 2015;112:201411926.

39. Muchero W, Guo J, DiFazio SP, Chen J-G, Ranjan P, Slavov GT, Gunter LE, Jawdy S, Bryan AC, Sykes R, Ziebell A, Klápště J, Porth I, Skyba O, Unda F, El-Kassaby Ya, Douglas CJ, Mansfield SD, Martin J, Schackwitz W, Evans LM, Czarnecki O, Tuskan Ga. High-resolution genetic mapping of allelic variants associated with cell wall chemistry in Populus. BMC Genom. 2015;16:24

40. Sykes R, Yung M, Novaes E, Kirst M, Peter G, Davis M. High-throughput screening of plant cell-wall composition using pyrolysis molecular beam mass spectroscopy. Methods Mol Biol. 2009;581:169-83.

41. Mielenz JR, Bardsley JS, Wyman CE. Fermentation of soybean hulls to ethanol while preserving protein value. Bioresour Technol. 2009;100:3532-9.

42. Ciolacu D, Ciolacu F, Popa V. Amorphous cellulose-structure and characterization. Cellul Chem. 2011;45:13-21.

43. Sun Q, Foston M, Meng X, Sawada D, Pingali SV, O'Neill HM, Li H, Wyman CE, Langan P, Ragauskas AJ, Kumar R. Effect of lignin content on changes occurring in poplar cellulose ultrastructure during dilute acid pretreatment. Biotechnol Biofuels. 2014;7:150.

44. Esteghlalian R, Bilodeau M, Mansfield SD, Saddler JN. Do enzymatic hydrolyzability and Simons'stain reflect the changes in the accessibility of lignocellulosic substrates to cellulase enzymes? Biotechnol Prog 2001;17:1049-54.

45. Chandra R, Ewanick S, Hsieh C, Saddler JN. The characterization of pretreated lignocellulosic substrates prior to enzymatic hydrolysis, part 1: a modified Simons' staining technique. Biotechnol Prog. 2008;24:1178-85.

\section{Submit your next manuscript to BioMed Central and we will help you at every step:}

- We accept pre-submission inquiries

- Our selector tool helps you to find the most relevant journal

- We provide round the clock customer support

- Convenient online submission

- Thorough peer review

- Inclusion in PubMed and all major indexing services

- Maximum visibility for your research

Submit your manuscript at www.biomedcentral.com/submit

() Biomed Central 